\title{
Links between karst hydrogeological properties and statistical characteristics of spring discharge time series: a theoretical study
}

\author{
Authors, e-mail, affiliation: \\ ${ }^{1}$ Adeline DUFOYER, adeline.dufoyer@etu.univ-rouen.fr \\ ${ }^{1}$ Nicolas MASSEI, nicolas.massei@univ-rouen.fr \\ ${ }^{1}$ Nicolas LECOQ, nicolas.lecoq@univ-rouen.fr \\ ${ }^{2}$ Jean-Christophe MARECHAL, jc.marechal@brgm.fr \\ ${ }^{2}$ Dominique THIERY, d.thiery@brgm.fr \\ ${ }^{2}$ Didier PENNEQUIN, $\underline{\text { d.pennequin@brgm.fr }}$ \\ ${ }^{2}$ Pierre-Yann DAVID, py.david@brgm.fr \\ ${ }^{1}$ Normandie Univ, UNIROUEN, UNICAEN, CNRS, M2C, 76000 ROUEN, France \\ ${ }^{2}$ Bureau de Recherches Géologiques et Minières, BRGM, France
}

\begin{abstract}
Physics-based modeling of karst systems remains almost impossible without enough accurate information about the inner physical characteristics. Usually, the only available hydrodynamic information is the spring discharge at the karst outlet. Numerous works in the past decades have used and proven the usefulness of time series analysis applied to spring discharge, precipitations or even physico-chemical parameters, for interpreting karst hydrological functioning. The main objective of this work is to provide additional insights of to what extent the informative content of the hydrodynamic signal at karst springs is sensitive to karst aquifers internal physical properties. In order to address this issue, we undertake an empirical approach based on the use of both distributed and physics-based models, and on synthetic systems responses. A sensitivity analysis of time series methods was conducted on karst hydraulic and physical properties. For this purpose, forward modeling of flow through several simple, constrained and synthetic cases in response to precipitations is undertaken. It allows us to quantify how the statistical characteristics of flow at the outlet are sensitive to changes (i) one hydraulic parameter of the model and (ii) in conduit network geometry. The matrix/conduit exchange coefficient appeared clearly as a determinant model parameter in the spring discharge simulation. The auto- and cross correlation functions seem to be of particular interest for the understanding of the karst inner physics. Indeed, these functions are always different, despite not so pronounced configuration differences. This would highlight that there is an informative content within the spring discharge time series and the usefulness of such analysis methods.
\end{abstract}

Key Words: Autocorrelation / Cross correlation / Simulated spring discharge / Synthetic karst aquifer 


\section{Introduction}

According to Ford and Williams (2007), carbonate rocks occupy about $12 \%$ of the planet and they estimate that $7-10 \%$ of it is karst. Karst features, such as fractures, conduits or caves, mainly occur in carbonate rocks because of their dissolution caused by acidic rainfall infiltration. These complex characteristics make them substantially different from other aquifers (Bakalowicz, 2005): they present highly variable and heterogeneous physical properties, especially regarding the aperture diameters, which can vary over more than five orders of magnitude (Mayaud et al., 2014). Owing to such heterogeneities, which in addition remain almost impossible to evaluate at the scale of the whole karst system, modeling water flow in karst is always challenging.

Sauter et al. (2006) reviewed the different numerical groundwater flow models that have been widely applied as very helpful tools in conservation, management and protection of aquifers since the 60's. This study also discussed their advantages and disadvantages in terms of the investigation effort, practical applicability and capacity to simulate heterogeneities. Nowadays, two general approaches are applied on karst systems: conceptual and spatially distributed modeling. With conceptual models, global hydraulic response of the aquifer output (e.g. spring discharge) is simulated to an input signal (e.g. groundwater recharge, infiltrating rainfall...). Using this approach, spatial variations of hydraulic and physical properties are not considered: it gives an understanding of the overall water balance of the modeled karst system. With spatially distributed models, the modeled domain is discretized into a grid of homogeneous sub-units. Specific hydraulic properties are settled to each sub-unit and specific conditions are defined at the model boundaries. All parameters and conditions can be spatially and/or temporally variable. In order to use these modeling approaches, different mathematical descriptions are necessary because flow and transport behaviors occur differently in matrix, fracture and conduit systems (Ghasemizadeh et al. 2012).

However, applying distributed modeling approaches on karst aquifers is a particularly challenging issue. Mostly, the only available information is the rainfall and the spring discharge at the output of a watershed, and unfortunately, the inner physics of these systems is never well known. That is why modeling this type of aquifer using distributed and physics-based approaches remains almost impossible as they always lack accurate information about the inner physical characteristics. The challenge of distributed modeling applied on karst aquifers is therefore to cope with their high spatial heterogeneities.

Because of the difficulties to model karst hydrological functioning based on their physical properties, conceptual (lumped) or empirical models have been extensively used (KarstMod (Jourde et al. (2015), Mazzilli et al. (2017), www.sokarst.org), Jukić and Denić-Jukić (2009), Gardénia (Thiéry, 2014 (C) BRGM), TEMPO (Pinault, 2001 (C) BRGM), Baudement et al. (2017), Long et al. (2004)). However, a complementary type of approaches consisted of investigating the informative content of spring discharge hydrological time series to interpret and infer hydrogeological characteristics of karst aquifers (Mangin (1984), Labat (2000a, 2000b), Larocque et al. (1998), Massei et al. (2006), Padilla and Pulido-Bosch (1995)). Yet, such approaches all faced the same issue of how statistical or spectral properties of spring flow time series could actually be related to karst properties, karstification degree, importance of conduit vs matrix flows, etc. Other authors then investigated how the informative content of hydrological time series at the outlet of karst could be linked to such internal physical/hydrogeological characteristics:

Eisenlohr et al. (1997), using modeled karst structures highlighted that the shape of correlograms would depend on the contrast between quick- and base flow, but also on the hydrological event frequency during the analyzed period and on the ratio between diffuse and point-source infiltration.

Several authors also studied karst aquifers thanks to tracing methods (Atkinson 1977, Mangin 1975, Lepiller and Mondain 1986). Hauns et al. (2001) studied tracer breakthrough curves in karst conduits and correlated both retardation and dispersion with the conduit network. Ronayne (2013) estimated the influence of conduit network geometry on the solute transport in synthetic karst systems by using three measures of transport connectivity. 
Yet, none of them really investigated to what extent statistical characteristics of karst outflow time series were actually sensitive to the internal characteristics of karst systems that are responsible for the observed hydrological responses behavior. In other words, to what extent are outflow time series sensitive to internal properties of karst aquifers?

Here, we investigated how and to what extent spring discharge time series is sensitive to 1) network geometry, 2) recharge mode (diffuse or point-source recharge), 3) magnitude of matrix-conduit exchanges. The overall approach is a theoretical study of the relationships between karst outflow and the hydrogeological characteristics of these modeled aquifers. The approach is based on 1) the development of synthetic test cases used for forward modeling of spring flow, 2) the analysis of spring hydrographs the synthetic karst aquifer model. Keeping the same rainfall time series as input, and changing some internal physical properties within the synthetic test case, we finally explore the relationships between some statistical characteristics of the output time series and these internal physical properties.

The paper is organized as follows. A methodological section is presented as a first step, which purpose is to describe the physics-based models used and the modeling scenarios, as well as the time series analysis methods that will be applied in order to explore the links between hydrological variations and internal physical characteristics. Results of the forward modeling of flow through several simple, constrained and synthetic systems in response to rainfall time series are then presented and analyzed. The last part of this contribution concerns the possible links between statistical and characteristics of the simulated hydrodynamic time series, and the inner physical properties of the modeled domains.

\section{Methodological approach}

As mentioned before, the overall methodology followed corresponds to an empirical approach based on the analysis of spring flow time series generated from forward modeling of hydrological response to a precipitation time series using synthetic test cases built from a physics-based model. It then involves 1) the use of a physicsbased, distributed aquifer model for generating test cases with controlled physics and parametrization, 2) the use of time series analysis for exploring the informative content of the time series released by the model.

\subsection{The MARTHE aquifer model}

Ghasemizadeh et al. (2012) have proposed an overview of the different modeling approaches applied on karst aquifers: double-porosity models better account for the dual character of karst aquifers, compared to the equivalent porous media approach. These models use one continuum with a relatively small hydraulic conductivity but a high storage capacity (usually matrix), and another continuum with a high hydraulic conductivity and a small storativity. They have been successfully used for spring discharge and water-table fluctuation simulation (Teutsch, 1993) and tracer transport simulation (Worthington and Smart 2003, Morales et al. 2007, Bailly-Comte et al. 2011, Ronayne 2013).

MARTHE (Modeling of Aquifers with a Rectangular mesh in Transient state for the Hydrodynamic calculation of hEads and flows) (Thiéry, 2015) is a software package designed by the BRGM for transient state hydrodynamic modeling of flows in three-dimensional or multi-layered porous media. The resolution uses the finite volume approach, implicit in space and explicit in time by establishing the exchange flow rates between a cell and its neighbors. The conservative mass equation, linked to Darcy's law, leads to the following one in confined aquifer:

$$
\operatorname{div}(K \operatorname{grad} H)+q=S_{S} \frac{\partial H}{\partial t}
$$

With:

- $\quad K$ the hydraulic conductivity $\left[\mathrm{m} \cdot \mathrm{s}^{-1}\right]$

- $\quad H$ the hydraulic head [m] 
- $\quad$ q the injected or pumped flow rate density (flow rate per unit volume: $\mathrm{m}^{3} \cdot \mathrm{s}^{-1}$ )

- $\quad t$ the time $[s]$

- $\quad S_{s}$ the confined specific storage coefficient $\left[\mathrm{m}^{-1}\right]$

The exchanges between the central cell $(\mathrm{C})$ and its neighbors $(\mathrm{N})$ are expressed as follow:

$$
Q+\sum_{N=1}^{6} T_{N C}\left(H_{E N}-H_{E C}\right)=\operatorname{SurfS} \frac{\left(H_{E C}-H_{B C}\right)}{\mathrm{d} t}
$$

With:

- $Q$ the external flow rate of the central cell $\left[\mathrm{m}^{3} \cdot \mathrm{s}^{-1}\right]$ (positive if flow is injected, negative if flow is withdrawn)

- $\quad \mathrm{T}_{\mathrm{NC}}$ the exchange transmissivity between cells $\mathrm{N}$ and $\mathrm{C}\left[\mathrm{m}^{2} \cdot \mathrm{s}^{-1}\right]$

- Surf, the cell horizontal area $\left[\mathrm{m}^{2}\right]$

- $\quad \mathrm{H}_{\mathrm{BC}}$ the hydraulic head at the center, at the beginning time step [m]

- $\quad H_{E C}$ the hydraulic head at the center, at the end time step [m]

- $H_{E N}$ the hydraulic head at the neighbor cell $N$, at the end time step [m]

- $\quad d t$ the duration of the time step [s]

MARTHE comprises a conduit network package, allowing the modeling of two types of drains: "classic drains" which can only drain the aquifer and never supply it, and "conduit drains" which allow matrix/conduit exchanges thanks to the porous wall. These last ones seem to be suitable for finely modeling karst conduits. Several specific parameters must be set for every cell containing a conduit: the dimension of the conduit (length, height, width), the conduit-network bottom altitude, the matrix-conduit exchange parameter and the conduit hydraulic conductivity. The matrix-conduit exchange parameter, $\mathrm{C}_{\mathrm{Ex}}$, is a multiplicative factor on the matrix permeability which is generally inverted in modeling problem resolutions. The exchange flow between matrix and conduit is calculated as follow:

$$
Q_{E x}=C_{E x} K_{M} \operatorname{Sat}_{D} L\left(H_{M}-H_{C}\right)
$$

with:

- $\quad \mathrm{K}_{\mathrm{M}}$, the matrix hydraulic conductivity $\left[\mathrm{m} \cdot \mathrm{s}^{-1}\right]$

- Sat $_{D}$ the saturation coefficient within the conduit, automatically calculated by MARTHE, which can vary from 0 (empty conduit) to 1 (saturated conduit).

- $\quad \mathrm{L}$, the conduit length [m]

- $\quad \mathrm{H}_{\mathrm{C}}$ the conduit hydraulic head [m]

- $\quad H_{M}$ the matrix hydraulic head [m]

The conduit flow rate $Q_{c N}$ coming from the neighboring conduit (adjacent section) is:

$$
Q_{C N}=A_{N} K_{C} \frac{H_{N C}-H_{C}}{L_{N}}
$$

with:

- $A_{N}$ the cross section between the conduit and its neighbor $\left[\mathrm{m}^{2}\right]$

- $\quad \mathrm{K}_{\mathrm{C}}$, the conduit hydraulic conductivity $\left[\mathrm{m} \cdot \mathrm{s}^{-1}\right]$

- $\quad L_{N}$ the distance from the neighbor [-]

- $\quad \mathrm{H}_{\mathrm{NC}}$ the hydraulic head in the neighboring conduit [m]

- $\quad \mathrm{H}_{\mathrm{c}}$ the hydraulic head in the calculation conduit [m]

The conduit hydraulic conductivity can be interpreted, with $U_{c}$ is the velocity within the conduit, as follow: 


$$
\frac{1}{K_{C}}=\frac{H_{N C}-H_{C}}{U_{C} L_{N}}
$$

The external flow rate can be positive if injected and negative if withdrawn.

\subsection{Synthetic test cases, modeling scenarios and model output analysis}

\subsubsection{Synthetic domains geometry and hydrogeological parameters}

In order to assess the sensitivity of the statistical characteristics of the output time series, one would have to first define those specific types of synthetic cases and select the inner physical properties or parameters to be accounted for in the overall process. Owing to a huge amount of possible test cases, we eventually had to select a limited number of physical or model parameters and focus on those which we considered the most important in terms of influence on flow dynamics. Two different domains were modeled using MARTHE (Figure 1): a monoconduit domain, which is considered and called "mono-conduit case", and a multi-conduit network, called "multiconduit case". Although the multi-conduit case may not appear as a "realistic " karstic case, it would actually correspond quite well to the so-called "network maze" karst type as described in Palmer's classification (Palmer, 1991). Such a karst type can also be thought of as a transition between intensively fissured media and pure karst; in this sense, it would fit quite well the double-porosity approach and the associated physics resolved in MARTHE.

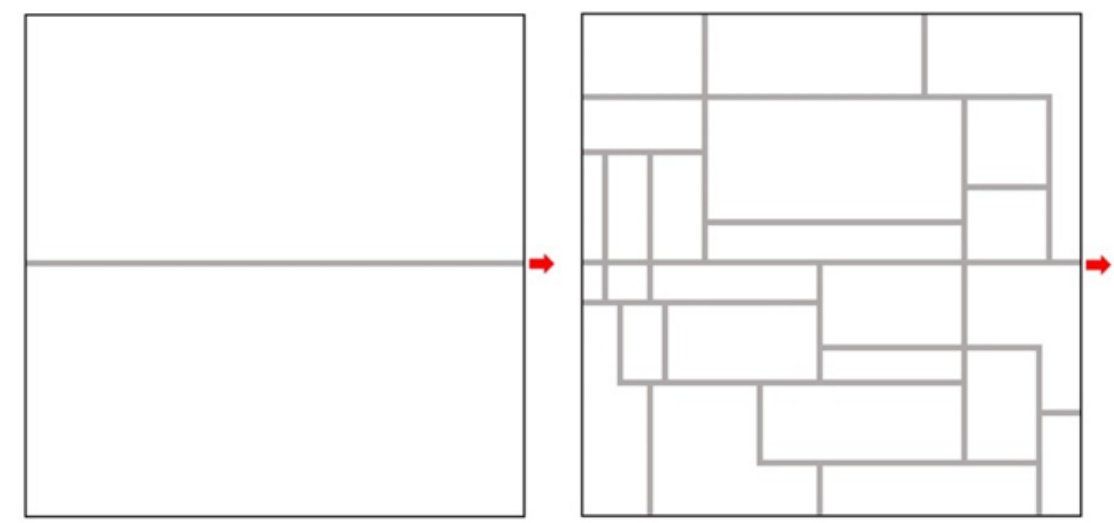

Figure 1. Mono-conduit model (left) and multi-conduit model (right) geometries: the white part is matrix, the grey lines represent conduits and the arrow indicates the spring

Both mono- and multi-conduits cases have conduits with same constant diameters. The objective here was to observe the influence of a greater complexity of conduit geometry on the hydrodynamic response. These models were built on the same $1 \mathrm{~km}^{2}$ grid and on the same standard hydraulic properties (Table 1). Hydraulic conductivity used for conduits was defined according to Sauter (1992) and Kiraly (1998). For the matrix, hydraulic conductivity was chosen sufficiently high to ensure enough exchanges with the conduit network.

Table 1. Modeled domains hydraulic properties

\begin{tabular}{|c|c|c|c|}
\hline \multicolumn{2}{|l|}{ Grid } & \multicolumn{2}{|l|}{ Karst conduit } \\
\hline $\begin{array}{l}\text { Number of columns } \\
\text { Number of lines } \\
\text { Col. width = Line height } \\
\text { Matrix }\end{array}$ & $\begin{array}{l}100 \\
100 \\
10 \mathrm{~m}\end{array}$ & $\begin{array}{l}\text { Conduit hydraulic conductivity, } \mathrm{K}_{\mathrm{C}} \\
\text { Exchange coefficient, } \mathrm{C}_{\mathrm{Ex}} \\
\text { Volume : } \\
\text { - } \quad \text { Height }=\text { width } \\
\text { - } \quad \text { Length per cell }\end{array}$ & $\begin{array}{l}10 \mathrm{~m} \cdot \mathrm{s}^{-1} \\
1 \\
10 \mathrm{~m}^{1} \mathrm{~m}\end{array}$ \\
\hline $\begin{array}{l}\text { Hydraulic conductivity, K } \\
\text { Confined specific storage, Ss }\end{array}$ & $\begin{array}{l}10^{-4} \mathrm{~m} \cdot \mathrm{s}^{-1} \\
5 \times 10^{-4} \mathrm{~m}^{-1}\end{array}$ & Elevation of the conduit bottom, $\mathrm{z}$ & $-50 m$ \\
\hline
\end{tabular}


Bauer et al. (2003) have already studied the sensitivity of matrix-conduit exchange parameter in karst conduit development modeling. They referred to Barenblatt et al. (1960), Warrenf and Root (1963), Narasimhan (1982) and Lei (1999) to calculate the exchange flux between matrix and conduit systems as a mathematical product of the hydraulic head differences between them and a $\alpha_{0}$ coefficient. This term lumped geometrical and hydraulic properties of the karst system. In their study, a $\alpha_{0}$ variation ranging from $1 \times 10^{-8}$ to $1 \times 10^{-4} \mathrm{~m}^{2} \mathrm{~s}^{-1}$ was used, corresponding to a $\mathrm{C}_{\mathrm{Ex}}$ variation range from $10^{-5}$ to 0.1 .

Kordilla et al. (2012) used a high exchange parameter value in their calibrated models such that it does not prevent water transfer between both continua. They used a value of 1 , after showing the sensitivity only for strong reduction of 3 to 4 orders of magnitude.

Several tests allowed us to observe that:

- Under a $\mathrm{C}_{\mathrm{Ex}}$ of 0.1 , the modeled aquifers do not react as karst ones and the calculated spring discharges are too much smoothed.

- Above a value of 2, there are no more noticeable differences in the calculated spring discharges.

Consequently, we chose to vary the exchange parameter from 0.1 , corresponding to small exchanges, to 1.5 , corresponding to significant amount of exchanges between conduits and matrix.

The boundary conditions, in these semi-confined aquifers, remained exactly the same for all simulations:

- The time step 0 allowed model initialization and steady state conditions were initially set.

- Hydraulic heads were imposed on the first and last columns cells: $60 \mathrm{~m}$ for column 1 and $55 \mathrm{~m}$ for column 100 , creating a natural hydraulic gradient of $5 \%$.

- The transient state was defined from time step 1 to the end of each simulation. A constant 55-m hydraulic head was imposed on the spring cell, while all the other domain limits were considered as impermeable.

\subsubsection{Input signals}

Since we are only interested in input signal transformation by internal properties of the karst system, all input signals are considered pure recharge.

A high amplitude pulse, i.e. a Dirac-like input signal, was firstly used, corresponding to a significant one-timestep-duration recharge, here $100 \mathrm{~mm}$ during one day. Although not realistic, the objective was to observe how the modeled systems transform the simplest input signal as possible, during the 50 days following the system solicitation. Spring discharge maxima, as well as the input/output delays were examined.

The second applied input mode was a twenty-year-duration observed rainfall time series, so that input statistical characteristics correspond to reality. This last type of recharge aims to release an output spring flow time series that would correspond more closely to realistic responses.

\subsubsection{Recharge modes}

Two recharge modes were chosen to set input signals on the modeled domains:

- A diffuse recharge process: the Dirac and the rainfall time series were uniformly imposed on the top of the domains. The surrounding matrix is therefore refilling the conduit network. 
- A point-source recharge process, which corresponds to a recharge directly settled at the conduit inlet and so, it is defined as an injected flow rate. The point-source Dirac and daily rainfall of the time series were recalculated in order to have the same quantity using this recharge way than when using the previous one:

$$
Q\left[m^{3} \cdot s^{-1}\right]=\frac{P_{\text {effective }}[\mathrm{m}] S_{\text {domain }}\left[\mathrm{m}^{2}\right]}{86400[\mathrm{~s}]}
$$

With:

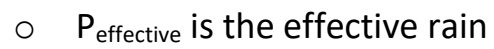

- $S_{\text {domain }}$ the surface of the modeled domain

\subsection{Time series analysis methods}

The use of pulse input function (thereafter called "Dirac" for simplification purpose) allows for producing one single hydrograph at the outlet that can be used for analyzing the link between physical characteristics and hydrological response. In real case applications, however, the input signal corresponds to a rainfall time series. In such cases, hydrological response at the outlet is a time series corresponding to the superposition of several hydrographs (e.g. scaled and lagged unit hydrographs). Analyzing such responses requires the use of time series analysis methods.

Several ways and methods, either in time or frequency domains, can be used to extract the available information in a time series and compute statistical characteristics or metrics characterizing its variability. In this study we focused on a few simple characteristics that can be quantified in the time domain and determined by computing autocorrelation functions of output signals and input/output cross-correlation functions.

Autocorrelation function quantifies the linear dependency of successive values over time. In smoother time series, successive values tend to be relatively close to each other and consequently, the autocorrelation function decreases slowly. On the contrary, rather rough time series (i.e. Gaussian white noise) display much lower correlation between successive values, giving sharply decreasing autocorrelation function. Daily rainfall time series are usually poorly autocorrelated time series. Hydrological systems smooth rainfall time series more or less extensively, leading to more autocorrelated outflow time series. Such a filtering depends on the internal characteristics of the system: for example, very karstified and transmissive system would not operate any significant smoothing of the input, hence resulting in low autocorrelated spring discharge. Autocorrelation can then provide an estimation of either the karstification degree of the system or the volume of water within it (Mangin 1984, Larocque et al. 1998, Labat et al. 2000b, Panagopoulos and Lambrakis 2006).

Autocorrelation function analysis allows quantifying the time series memory effect by calculating the linear dependence of a value at each step on previous ones. Autocovariance function $C_{k}$ and autocorrelation function $r_{k}$ are defined thanks to the following equations:

$$
\begin{gathered}
C_{k}=\frac{1}{n} \sum_{t=1}^{n-k}\left(x_{t}-\bar{x}\right)\left(x_{t+k}-\bar{x}\right) \\
r_{k}=\frac{C_{k}}{C_{0}}
\end{gathered}
$$

With:

- $k$, the time delay

- $n$, the length of the studied time series

- $x_{t}$, the series value at the time $t$

- $\quad \bar{x}$, the mean value of the series 
Autocorrelation coefficients are calculated from 0 to $\mathrm{m}$, with $\mathrm{m}$ usually corresponding to a third of the chronic length (Mangin, 1984). Historically, the memory effect of the karst is defined as the lag corresponding to an autocorrelation coefficient of 0.2 (Mangin 1984, Padilla and Pulido-Bosch 1995, Larocque et al. 1998, Labat et al. 2000a, Mathevet et al. 2004, Panagopoulos and Lambrakis 2006, Massei et al. 2006).

Although the memory effect would actually correspond to the overall behavior of the autocorrelation function, lag time for coefficient 0.2 would be enough informative to compare amongst different time series

Cross-correlation provides the same type of information through the comparison between spring discharge and rainfall. Amplitude of linear correlation, time lag between input and output time series and the duration of the cross-correlation function are particularly examined. Moreover, cross-correlation function can be readily related to the impulse response function of the hydrosystem (i.e. the unit hydrograph).

Cross-correlation analysis aims to quantify the linear depending between two variables, here rainfall and discharge, as a function of the time delay. The cross-covariance $C_{x y}(k)$ and the cross-correlation functions $r_{x y}(k)$ are defined as follow:

$$
\begin{gathered}
C_{x y}(k)=\frac{1}{n} \sum_{t=1}^{n-k}\left(x_{t}-\bar{x}\right)\left(y_{t+k}-\bar{y}\right) \\
r_{x y}(k)=\frac{C_{x y}(k)}{\sigma_{x} \sigma_{y}}
\end{gathered}
$$

With:

- $\quad k$, the time delay

- $\quad n$, the length of the studied time series

- $x_{t}$ and $y_{t}$ respectively the time series values at time $t$

- $\quad x$ and $y$, respectively the $x$ and $y$ time series mean values

- $\sigma_{\mathrm{x}}$ and $\sigma_{\mathrm{y}}$, respectively the $\mathrm{x}$ and $\mathrm{y}$ time series standard deviations

Cross-correlogram can take different shapes:

- If $R_{x y}(k)>0$, there is a correlation between the two signals

If $K>0$, the input influences the output

- If $\mathrm{K}<0$, the output influences the input

- If $R_{x y}(k)<0$, there is an anti-correlation between the two signals

- If $K>0$, the input influences the output

$\circ$ If $K<0$, the output influences the input

The impulse response image, considered as the response time, is a quantitative indicator defined as the time between $\mathrm{k}=0$ and the $r_{\mathrm{xy}}(\mathrm{k})$ maximum. If several peaks are observed, it can be artefacts but sometimes they can indicate distinct responses of the system linked to the porosity heterogeneities (Padilla and Pulido-Bosch 1995). 


\section{Modeled response to pulse input}

\subsection{Dirac-type recharge}

Mono-conduit case

a.

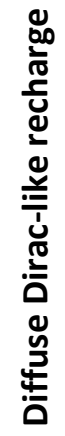

c.

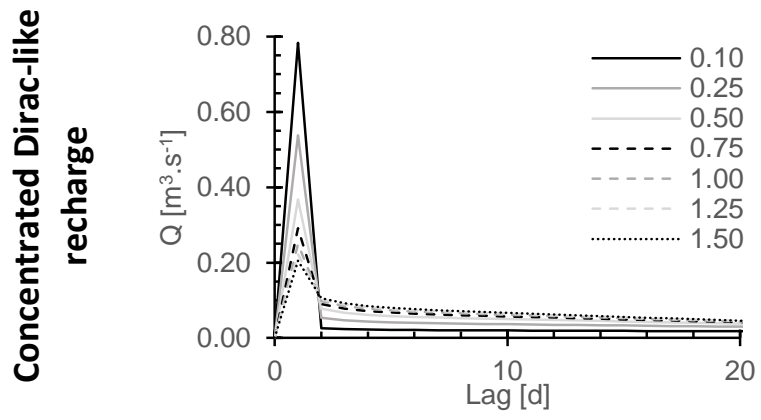

Multi-conduit case

b.

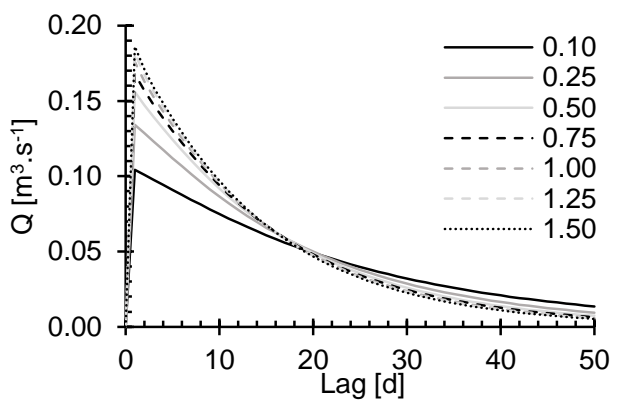

d.

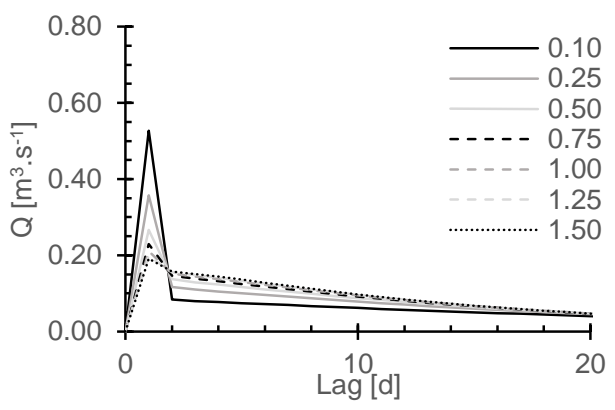

Figure 2. Simulated hydrographs for Dirac-like recharge: $a$. and b., respectively mono- and multi-conduits cases, under diffuse recharge conditions, $c$. and d. respectively mono- and multi-conduits cases, under pointsource recharge conditions

\subsubsection{General observations}

Regardless of the recharge conditions and the modeled domains, the maximum discharge values are always obtained at day 1, i.e. one day after the recharge application (Figure 2). Moreover, diffuse pulse recharge always produces a lower peak flow than the one obtained with a point-source recharge (Figure 2 a., Figure 2 b.). Finally, except for the point-source recharge, mono-conduit case peak flows (Figure $2 \mathrm{c}$.) are always smaller than the multi-conduit case ones (Figure $2 \mathrm{~d}$.). This can be explained by the amount of conduits within the domain:

- With diffuse recharge conditions, water inputs are settled on the entire surface of the domain, involving a more important time delay to reach the only conduit of the mono-conduit case than the one needed in the multi-conduit case.

- With point-source recharge, water inputs are settled at the conduit entrance, on the left limit, and, in the mono-conduit case, water has only one travel possibility (i.e. with one single conduit) while in the multi-conduit case, there are more possibilities (i.e. through a network of conduits), involving a lower peak flow, but a slower decrease. 
When using a point-source Dirac recharge mode (Figure 2 c., Figure 2 d.), the global shape of the unit hydrographs is different than the one obtained with a diffuse Dirac recharge (Figure 2 a., Figure 2 b.). Two distinct parts are still obtained with a really more pronounced main peak and a clear recession limb (Figure 2 c., Figure 2 d.).

The comparison between the maximum discharge values shows that there are not huge differences between the two modeled domains, regardless of the recharge condition. Certain specific parameter values and conditions provide noticeable differences: all exchange parameter values with diffuse Dirac recharge, and for $\mathrm{C}_{\mathrm{Ex}}<1$ with the point-source Dirac recharge.

\subsubsection{Diffuse input}

Figure 2 sustains what was said before: the peak flow is always reached at day 1, immediately after the perturbation. After reaching its maximum value, spring discharges follow a rather slow decay for most cases. Indeed, some parameters seem to control more the spring discharge fluctuations: different variation ranges can be observed with respect to the modulated parameter: when $C_{E x}$ is higher than 1 , there is no more significant differences in spring discharge.

\subsubsection{Point-source input}

In addition to the global shape of the recession curves, there are significant differences between the peak flow values with respect to the recharge mode. Logically, spring discharges obtained with a point-source recharge are almost always higher than the ones obtained with the diffuse Dirac, and the differences between the flow modeled by diffuse and point-source Dirac is more significant in the mono-conduit case. The behavior of the recession curves obtained by the variation of the exchange parameter is totally different when using a pointsource recharge than when using a diffuse one: peak flow higher with a smaller value. This observation seems logical because recharge is directly applied at the entrance of the conduit/conduit network, which means that with a low exchange parameter, most of the water stays within the conduits.

\subsection{Response to rainfall recharge}

\subsubsection{Autocorrelation functions (ACF)}

The autocorrelation function of the rainfall time series sharply decreases, even for lag values close to zero. The autocorrelation coefficient remaining close to zero, with no visible periodicities, means that no memory effect can be detected in rainfall, it therefore behaves like a pure white noise.

The autocorrelation functions were calculated for every simulated spring discharges (Figure 3). Figure 3a. shows that, in the mono-conduit case under a diffuse recharge, the ACF is firstly strong for low $C_{E x}$ and then, after a value of 0.5 , all the obtained curves are overlapping. In the multi-conduit case (Figure $3 \mathrm{~b}$.), the differences between the ACF are not as well marked as the previous ones and the curves are quasi-overlapping, even for low $\mathrm{C}_{\mathrm{Ex}}$. The comparison of the different autocorrelation functions calculated under diffuse recharge conditions shows that the memory effect is more important when there is only one conduit than when there is a network of conduits. Under these conditions, when $\mathrm{C}_{\mathrm{Ex}}$ is increasing, the memory effect is decreasing and the signal is therefore more noised with a high $\mathrm{C}_{\mathrm{Ex}}$ or more smoothed with low $\mathrm{C}_{\mathrm{Ex}}$.

Comparing Figure $3 a$. and b. with Figure $3 c$. and d. shows the particular influence of the recharge mode on the autocorrelation amplitude: the ACF calculated under diffuse recharge conditions are stronger than the ones calculated under point-source recharge. Once this last is applied on the modeled domains, there is a larger responses dispersion. 
1-Conduit Case

a.

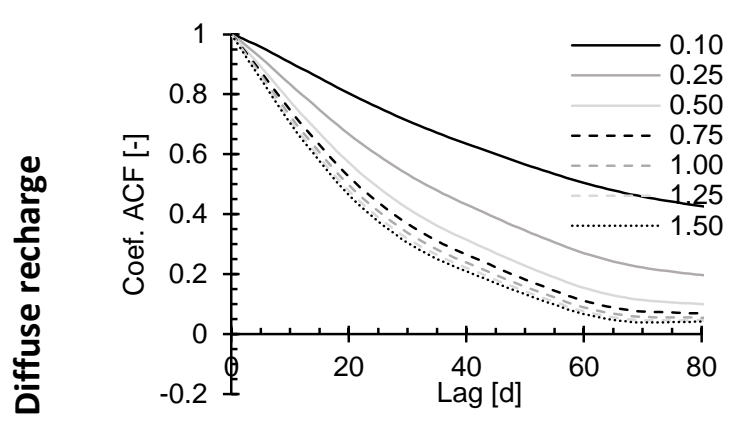

C.

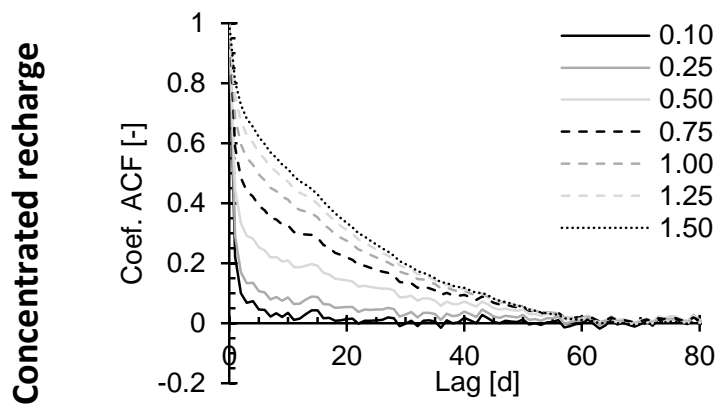

Multi-Conduit Case

b.

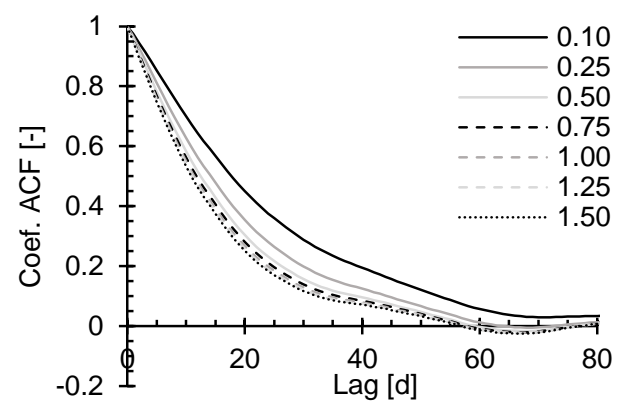

d.

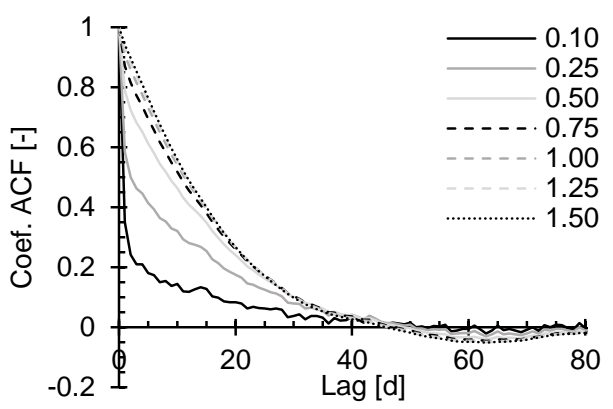

Figure 3. Autocorrelation functions calculated on the simulated spring discharge time series: $a$. and $b$. respectively for the mono- and multi-conduits cases, under diffuse recharge conditions, c. and d. respectively for the mono- and multi-conduits cases, under point-source recharge conditions

The importance of the exchange parameter on the hydrodynamic responses is better observed when specifically looking at Figure $3 \mathrm{c}$. For $\mathrm{C}_{\mathrm{Ex}}$ lower than 0.75 , two distinct parts are clearly observable on the autocorrelation functions: a very quick decrease followed by a gentle slope. These two parts are only as notable on the multiconduit cases (Figure $3 \mathrm{~d}$.) with a $\mathrm{C}_{\mathrm{Ex}}$ lower than 0.50, a possible threshold value from which there is no longer conduit signature.

Nevertheless, there are slight differences between the modeled domains under point-source recharge conditions (Figure 3c. and Figure $3 \mathrm{~d}$.). When $\mathrm{C}_{\mathrm{Ex}}$ is lower than 0.75 , the multi-conduit ACF is stronger than the mono-conduit one, meaning that the network complexity is more smoothing the signal thanks to its diffusion capability. On the other hand, when the exchange parameter used allows a consequent amount of exchanges between conduits to matrix, the mono-conduit ACF is stronger than the multi-conduit one. In the multi-conduit case, groundwater can easily flow within the conduit network, because of its high diffusion capacity, unlike in the mono-conduit case in which groundwater has to pass through the conduit to the matrix. Moreover, flow is easier directly within the conduits than if it has to pass through conduit to matrix before coming back to conduit. In that respect, with a high conduit/matrix exchanges capacity, a well-developed network is less smoothing the input signal than a single-conduit domain. 


\subsection{Rainfall/Discharge cross-correlation functions (CCF)}

For cross-correlation functions, only the positive part of the $x$-axis should be interpreted, as only this part expresses the causal relationship between input and output.

1-Conduit Case

a.

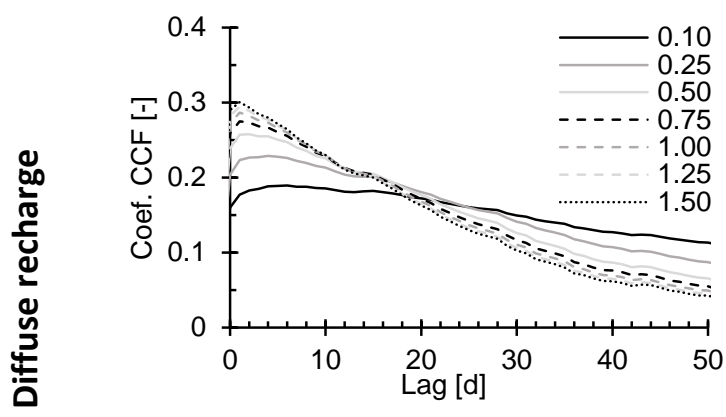

c.

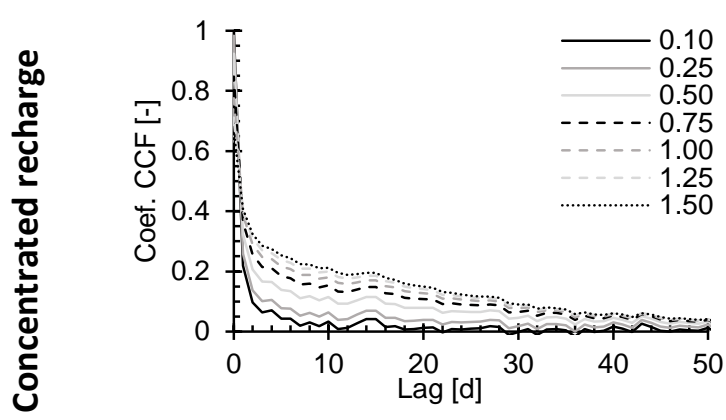

e.

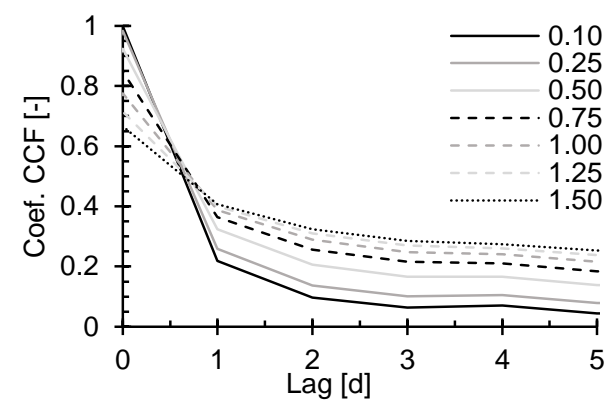

Multi-Conduit Case

b.

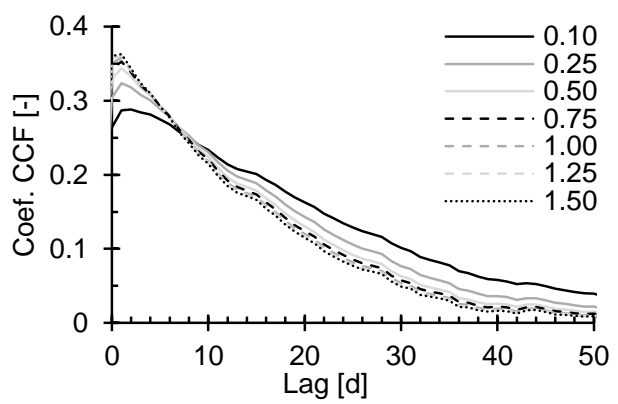

d.

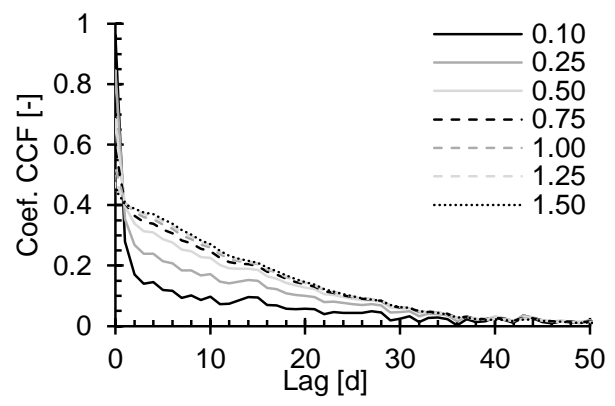

f.

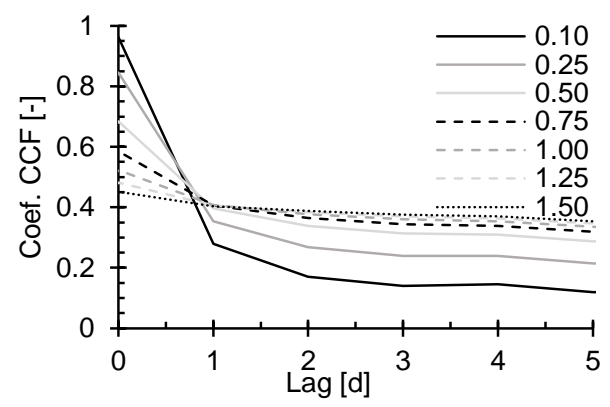

Figure 4. Cross correlation functions calculated on the simulated spring discharge time series: $a$. and b. respectively for the mono- and multi-conduits cases, under diffuse recharge conditions, c. and d. respectively for the mono- and multi-conduits cases, under point-source recharge conditions, e. and f. respectively enlargements of $\mathrm{c}$. and $d$

Under diffuse recharge conditions, Figure $4 \mathrm{a}$. and Figure $4 \mathrm{~b}$. indicate a weak correlation between rainfall and simulated spring discharge time series (around 0.3). Comparing these two plots also allows observing a stronger cross-correlation when the conduit network is more developed. For the same $C_{E x}$, the CCF is always reaching higher maximum values in the multi-conduit case because of the conduit interception probability. Both plot also indicates that when $\mathrm{C}_{\mathrm{Ex}}$ is decreasing, there is a clear decrease in the correlation peak value and a spreading of the curve. This last observation can be linked to the phenomenon of diffusion within the matrix. However, in the 
multi-conduit cases, because of the amount of conduits within the modeled domain, the spreading is less pronounced and the sensibility to $\mathrm{C}_{\mathrm{Ex}}$ is minimized, compared to the mono-conduit ones.

As with a point-source Dirac-like recharge, the cross-correlation functions plotted on Figure 4 c,e and Figure 4 $d$, f show two different behaviors: a very quick response, with no-delay, and a slower one. Thanks to this type of recharge, the correlation is always very high, regardless of the karst network complexity. The fewer conduit/matrix exchanges there are, the quicker the cross-correlation functions are falling close to zero, and conversely, the more exchanges there are, the more smoothed the decreasing part is.

Nevertheless, the spreading of the cross-correlation functions present differences between the mono- (Figure 4 $c, e)$ and multi-conduit cases (Figure $4 \mathrm{~d}, \mathrm{f}$ ): the spreading is stronger for the mono-conduit case.

\section{Discussion}

\subsection{Role of matrix/conduit exchange parameter}

Figure 5 and Figure 6 synthetize the results of autocorrelation and cross-correlation functions, respectively. For autocorrelation functions, the memory effect is taken as the lag corresponding to an autocorrelation coefficient of 0.2 . The results of autocorrelation functions show that the memory effect tends to decrease when the exchange parameter increases under diffuse recharge conditions, and conversely in the case of point-source recharge (Figure 5). This effect is less pronounced for the multi-conduit case. Beyond exchange parameter values of about 0.5 , the memory effect tends to stabilize and all configurations but the mono-conduit/diffuse recharge reach similar memory effects.

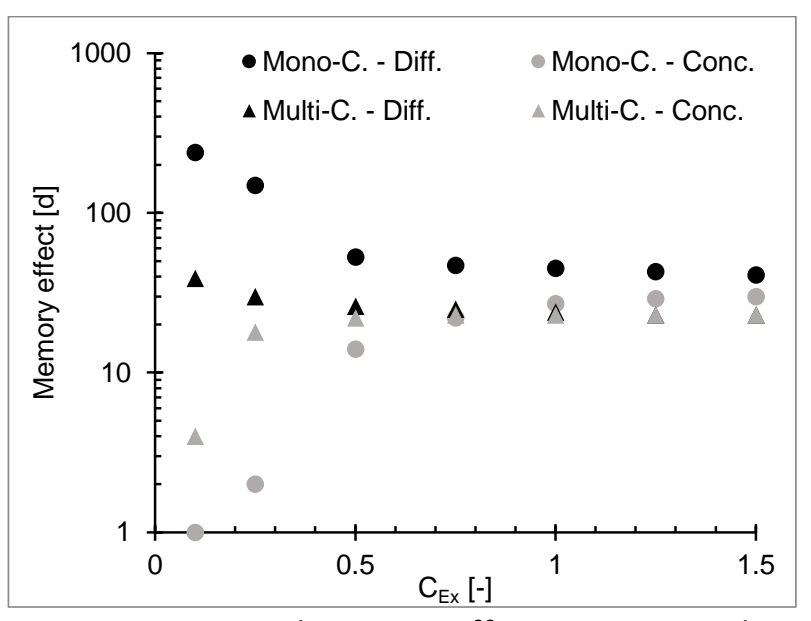

Figure 5. Estimated memory effects, corresponding to an autocorrelation coefficient of 0.2 , as a function of the exchange parameter value for the mono- and multi-conduits cases, under diffuse and point-source recharge conditions

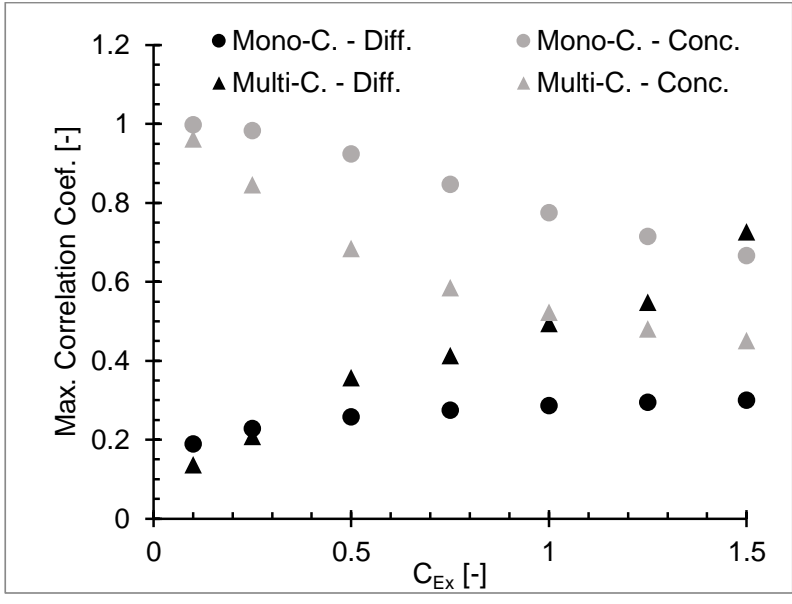

Figure 6. Correlation peak as a function of the exchange parameter value for the mono- and multiconduits cases, under diffuse and point-source recharge conditions

Cross-correlation functions behave approximatively the same way. Maximum cross-correlation is obtained for point-source recharge and tends to decrease with increasing exchange parameter, and conversely for diffuse recharge scenarios

A high exchange parameter allows for diffuse recharge to more easily reach the conduit network (and conversely for low exchange parameter). This would then favor the transfer to the conduits and thus the drainage of the matrix by the network, hence a lower autocorrelation in outflow at the spring, as conduit flow is less of a smooth signal. This also explains that rainfall/spring discharge correlation is increasing (Figure 6), even more as the karst 
network is more developed within the domain (i.e. mono-conduit vs. more developed multi-conduit). The overall behavior of autocorrelograms (Figure 3) reflects this phenomenon with the spreading of the calculated ACF (Figure $3 a, b$ ), as well as the pulse responses (Figure $2 a, b$ ): the value of the peak flow decreases, showing less drainage by conduits.

Under point-source recharge conditions, the memory effect globally increases with exchange parameter until $C_{E x}$ $\sim 0.5$, which can easily be interpreted in more water entering the matrix surrounding the conduit network. With more conduits (multi-conduit case), the memory effect consistently increases more slowly compared to the mono-conduit as the network allows for more flow before getting under enough pressure to force water into the matrix. For the same reasons correlation of spring flow with rainfall is higher for point-source recharge. Higher correlation for the mono-conduit configuration can be explained by fast pressure-pulse transfer as the monoconduit remains under pressure even when $C_{E x}$ increases, which could affect the multi-conduit configuration to a much lower extent.

The distinction between the two flow modes is very clear (in conduits, and in the matrix around conduits), on pulse responses (Figure $2 \mathrm{c}, \mathrm{d}$ ) and on auto- (Figure $3 \mathrm{c}, \mathrm{d}$ ) and cross-correlograms (Figure $4 \mathrm{c}, \mathrm{d}, \mathrm{e}, \mathrm{f}$ ). As emphasized earlier, when $\mathrm{C}_{\mathrm{Ex}}$ decreases, (i) the duality of the response is gradually lost, to the benefit of the conduits, and (ii) the peak flow and the intensity of rainfall/spring discharge correlation increases. This seems particularly logical because the more solicited conduits regarding the matrix, the less filtered the rainfall by the karst aquifer, and the most important the rainfall/spring discharge correlation.

\subsection{Role of the network geometry}

The influence of the geometry, i.e. the density of the network (single- or multi-conduits), appears strongly dependent on the mode of recharge and matrix-conduit exchange parameter.

Under diffuse recharge conditions, a high network density favors the drainage of the matrix through the conduits. A high exchange parameter exacerbates this effect.

Under point-source recharge conditions, the opposite phenomenon is globally observed because the exchanges are mainly from conduits to the matrix, the water being injected directly into the conduits. The role of the conduits is more or less marked, depending on the intensity of the exchanges. For a very low exchange parameter, the hydrological response almost only involves the conduit network, and is fast and intense (peak flow (Figure $2 \mathrm{c}, \mathrm{d}$ ), auto- (Figure $3 \mathrm{c}, \mathrm{d}$ ) and cross-correlation (Figure $4 \mathrm{c}, \mathrm{d}, \mathrm{e}, \mathrm{f}$ )), such as a pressure-pulse transfer. This phenomenon is less marked in the multi-conduit cases, which would further disperse the flood wave because of the network complexity, compared to the mono-conduit cases. For a strong exchange parameter, on the other hand, the pulse responses, auto- and cross-correlograms all show higher peak flows and more marked correlations than the mono-conduit cases. There is also a slower decay than in the multi-conduit cases, because once the pressure-pulse transfer is achieved, the single-conduit cannot withstand as much water flow as the multi-conduit case, and is forced to exchange more water with the matrix that eventually empties in a longer recession.

\subsection{Uniqueness of the statistical responses}

The study shows that some of the analytical results may appear similar at first sight, but a thorough inspection highlights that they always present subtleties, meaning that different possibly important processes at play. For example, in the modeled test cases, the calculated lags (Figure 5) look similar for several modeled cases: looking more precisely at these memory effect estimations (Figure 5), the differences do not seem very marked for a $\mathrm{C}_{\mathrm{Ex}}$ higher than 0.5 . Yet, a detailed analysis of corresponding autocorrelation functions reveals that their overall behavior is always different. Figure 7 plots the four autocorrelation functions calculated for the modeled domains, with a constant exchange parameter, $\mathrm{C}_{\mathrm{Ex}}=0.75$ and it shows that, even if the lag corresponding to a 
coefficient of 0.2 is the same, the global trends of these functions are not similar. This highlights the question of the use of an autocorrelation coefficient of 0.2 to estimate the memory effect of an aquifer.

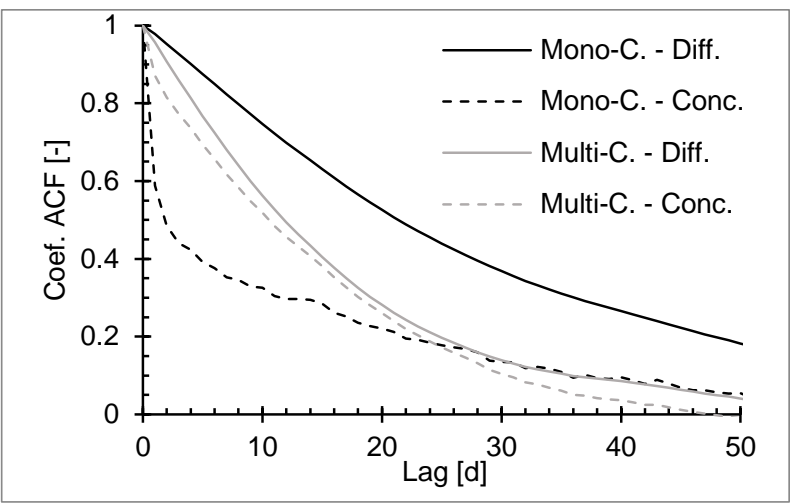

Figure 7. Comparison of the autocorrelation functions calculated for the mono- and multi-conduits cases, under diffuse and point-source recharge conditions with a constant $\mathrm{C}_{\mathrm{EX}}=0.75$

For instance, Massei et al. (2006) had proposed to fit logarithmic functions to account for an oversall behavior of the autocorrelation function. However, our results show that one need to carefully inspect the whole autoand cross-correlograms in order to detect the presence or absence of fast karstic response, superimposed or not to slow matrix-like responses (e.g. in the form of small spikes for the very first lags followed by a slow decrease of autocorrelation functions), etc. Nevertheless, this study highlights that the informative content of spring flow time-series is sensitive to some inner properties of karst hydrosystems, and its analysis should deserve more attention in the aim of improving the link between data, processes and models.

\section{Conclusion}

Numerical modeling simulation, conducted with the double-porosity model MARTHE, allowed creating theoretical and synthetic karst aquifers. Two different karst geometries were simulated: a simple domain with only one single conduit passing entirely through it, and a more complex one.

The objectives were to assess the influence of one of the model parameters, the matrix/conduit exchange parameter, and of two different karst geometries. The exchange parameter appeared clearly as a determinant model parameter in the spring discharge simulation. In this study, modeling theoretical karst aquifers with a low exchange parameter between matrix and conduit allowed highlighting the conduit network effects on the simulated spring discharge. Indeed, by both preventing the exchanges between conduits and matrix and using a point-source recharge mode, it is possible to erase the flow duality, to the benefit of the conduits. However, under diffuse recharge conditions, a dense conduit network logically allows for a better drainage of the matrix by the conduits, hence lower autocorrelation spring discharge compared to the mono-conduit case.

The auto- and cross-correlation functions, calculated on the simulated time series, seem to be of particular interest. Using variable matrix/conduit exchange parameter and recharge conditions always produces different auto- and cross-correlograms. In other words, it was not possible to obtain one common auto- or crosscorrelation function for two different hydrogeological configurations. This would highlight the usefulness of such time-series analysis methods to analyze the informative content of spring flow time-series in order to assess physical properties of karst systems.

Further research may involve the use of other methods for analyzing and interpreting the informative content of spring flow time series, such as frequency-domain or wavelet-based techniques, which provide additional statistical metrics time series variability. It would be also particularly interesting to consider other scenarios or synthetic test-cases based on realistic karst networks (from well-known network classifications for instance) to be include into the MARTHE model, or in another flow model accounting for more realistic karst flow processes 
such as discrete-continuum approaches. Finally, considering real observed data of well-constrained karst hydrosystems and networks would be crucial, although the present approach was precisely developed because of the lack of availability of such data.

\section{References}

Atkinson T.C. (1977) Diffuse flow and conduit flow in limestone terrain in the Mendip Hills, Somerset (Great Britain). J. Hydrol. 35:93-110

Bailly-Comte, V., Martin, J.B., Screaton, E.J. (2011) Time variant cross-correlation to assess residence time of water and implication for hydraulics of a sink-rise karst system. Water Resour. Res. 47, W05547

Bakalowicz M. (2005) Karst groundwater: a challenge for new resources. Hydrogeol J 13(1):148-160

Barenblatt G.I., Zheltov I.P., Kochina I.N. (1960) Basic concepts in the theory of seepage of homogeneous liquids in fissured rocks. J Appl Math Mech 24:1286-1303

Baudement C., Arfib B., Mazzilli N., Jouves J., Lamarque T., Guglielmi Y. (2017) Assessing floods and groundwater management of a highly dynamic karst with a reservoir model (Dardennes springs, SE France), BSGF. Earth Sciences Bulletin 188:40

Bauer, S., R., Liedl, and M. Sauter (2003) Modeling of karst aquifer genesis: Influence of exchange flo, Water Resour. Res., 39(10), 1285, https://doi.org/10.1029/2003wr002218\$̦

Eisenlohr L., Király L., Bouzelboudjen M., Rossier I. (1997) Numerical simulation as a tool for checking the interpretation of karst springs hydrographs. J. Hydrol. 193:306-315

Ford D.C., Williams P.W. (2007) Karst hydrogeology and geomorphology. Wiley, Chichester, UK, 576 pp

Ghasemizadeh, R., Hellweger, F., Butscher, C., Padilla, I., Vesper, D., Field, M., Alshawabkeh, A. (2012) Review: Groundwater flow and transport modeling of karst aquifers, with particular reference to the North Coast Limestone aquifer system of Puerto Rico. Hydrogeol J, 20(8):1441-1461

Hauns M., Jeannin P.Y., Atteia O. (2001) Dispersion, retardation and scale effect in tracer breakthrough curves in karst conduits. J. Hydrol. 241:177-193

Jourde H., Mazzilli N., Lecoq N., Arfib B., Bertin D. (2015) KARSTMOD - A generic modular reservoir model dedicated to spring discharge modeling and hydrodynamic analysis in karst. In: Andreo B., Carrasco F., Durán J., Jiménez P., LaMoreaux J. (eds) Hydrogeological and environmental investigations in karst systems Environmental earth sceinces, vol 1. Springer, Berlin, Heidelberg

Hydrogeol. Environ. Investig. Karst Syste. Springer, pp 339-344

Jukić D., Denić-Jukić V. (2009) Groundwater balance estimation in karst by using a conceptual rainfall-runoff model. J. Hydrol. 373 (3-4):302-315.

Kiraly, L. (1998) Modeling karst aquifers by the combined discrete channel and continuum approach, Bull. Hydrogeol., 16, 77-98

Kordilla, J., Sauter, M., Reimann, T., and Geyer, T. (2012) Simulation of saturated and unsaturated flow in karst systems at catchment scale using a double continuum approach, Hydrol. Earth Syst. Sci., 16, 3909-3923, https://doi.org/10.5194/hess-16-3909-2012

Labat D., Ababou R., Mangin A. (2000a) Rainfall-runoff relations for karstic springs. Part I: convolution and spectral analyses. J. Hydrol. 238 (3-4):123-148

Labat D., Ababou R., Mangin A. (2000b) Rainfall-runoff relations for karstic springs. Part II: continuous wavelet and discrete orthogonal multiresolution analyses. J. Hydrol. 238 (3-4):149-178 
Larocque M., Mangin A., Razack M., Banton O. (1998) Contribution of correlation and spectral analyses to the regional study of a large karst aquifer (Charente, France). J. Hydrol. 205:217-231

Lei, S. (1999) An analytical solution for steady state flow into a tunnel, Ground Water, 37, 23-26

Lepiller M., Mondain P.H. (1986) Les traçages artificiels en hydrogéologie karstique. Hydrogéologie (BRGM) 1:3352

Long A.J., Putnam L.D. (2004) Linear model describing three components of flow in karst aquifers using 180 data. J. Hydrol. 296 (1-4):254-270

Mangin A. (1975) Contribution à l'étude hydrodynamique des aquifères karstiques [Contribution to the hydrodynamic study of karst aquifers]. PhD Thesis, Institut des Sciences de la Terre de l'Université de Dijon

Mangin A., (1984) Pour une meilleure connaissance des systèmes hydrologiques à partir des analyses corrélatoires et spectrales. J. Hydrol. $67: 25-43$

Massei N., Dupont J.P., Mahler B.J., Laignel B., Fournier M., Valdes D., Ogier S. (2006) Investigating transport properties and turbidity dynamics of a karst aquifer using correlation, spectral, and wavelet analyses. J. Hydrol. 329:244-257

Mathevet T., Lepiller M., Mangin, A. (2004) Application of time-series analyses to the hydrological functioning of an Alpine karstic system: the case of Bange-L'Eau-Morte. Hydrology and Earth System Sciences 8(6):1051-1064

Mayaud C., Wagner T., Benischke R., Birk S. (2014) Single event time series analysis in a binary karst catchment evaluated using a groundwater model (Lurbach system, Austria). J. Hydrol. 511:628-639

Mazzilli N., Guinot V., Jourde H., Lecoq N., Labat D. et al. (2018) KarstMod: a modelling platform for rainfalldischarge analysis and modelling dedicated to karst systems. Environmental Modelling and Software. https://doi.org/10.1016/j.envsoft.2017.03.015

Morales T., Fdez. de Valderrama I., Uriarte J. et al. (2007) Predicting travel times and transport characterization in karst conduits by analyzing tracer-breakthrough curves. J Hydrol 334:183-198.

Narasimhan, T. N. (1982) Multidimensional numerical simulation of fluid flow in fractured porous media, Water Resour: Res., 18, 1235-1247

Padilla A., Pulido-Bosch A. (1995) Study of hydrographs of karstic aquifers by means of correlation and crossspectral analysis. J. Hydrol. 168 (1-4):73-89

Palmer A.N. (1991) Origin and morphology of limestone caves. Geological Society of America Geol Soc Am Bull 103:1-21.

Panagopoulos G., Lambrakis N. (2006) The contribution of time series analysis to the study of the hydrodynamic characteristics of the karst systems: Application on two typical karst aquifers of Greece (Trifilia, Almyros Crete). J. Hydrol. 329:368-376

Pinault J.L. (2001) Manuel utilisateur de TEMPO : Logiciel de traitement et de modélisation des series temporelles en hydrogéologie et en hydrogéochimie. Projet Modhydro. BRGM Report RP51459-FR, 221 p.

Ronayne M.J. (2013) Influence of conduit network geometry on solute transport in karst aquifers with a permeable matrix. Adv. Water Resour. 56:27-34

Sauter, M. (1992) Quantification and forecasting of regional groundwater flow and transport in a karst aquifer (Gallusquelle, Malm, SW Germany), Tübinger Geowiss. Arb. C13, 150 pp., Univ. of Tübingen, Tübingen, Germany

Sauter M., Kovacs A., Geyer T., Teutsch G. (2006) Modellierung der hydraulik von karst grundwasserleiter: eine übersicht [Modeling of the hydraulics of karst aquifers: an overview].Grundwasser 11(3):143-156 
Teutsch G. (1993) An extended double-porosity concept as a practical modeling approach for a karstified terrain. Hydrogeological Processes in Karst Terranes (Proceedings of the Antalya Symposium and Field Seminar, October 1990), IAHS, Wallingford, UK, pp 281-292

Thiéry D. (2014) Logiciel GARDENIA, version 8.2. Guide d'utilisation. Rapport BRGM/RP-62797-FR, 126 p., 65 fig., 2 ann.

Thiéry D. (2015) Code de calcul MARTHE - Modélisation 3D des écoulements dans les hydrosystèmes - Notice d'utilisation de la version 7,5. Rapport BRGM/RP-64554-FR, 306p., 150 fig.

Warren, J. E., and P. J. Root (1963) The behavior of naturally fractured reservoirs, Soc. Pet. Eng. J., 3, 245-255

Worthington S., Smart C. (2003) Empirical Determination of Tracer Mass for Sink to Spring Tests in Karst. Sink Eng Environ Impacts Karst 122:287-298 


\section{Figures captions}

Figure 1. Mono-conduit model (left) and multi-conduit model (right) geometry

Figure 2. Simulated hydrographs for Dirac-like recharge: a. and b., respectively mono- and multi-conduits cases, under diffuse recharge conditions, c. and d. respectively mono- and multi-conduits cases, under point-source recharge conditions

Figure 3. Autocorrelation functions calculated on the simulated spring discharge time series: $a$. and $b$. respectively for the mono- and multi-conduits cases, under diffuse recharge conditions, c. and d. respectively for the mono- and multi-conduits cases, under point-source recharge conditions.

Figure 4. Cross-correlation functions calculated on the simulated spring discharge time series: a. and b. respectively for the mono- and multi-conduits cases, under diffuse recharge conditions, c. and d. respectively for the mono- and multi-conduits cases, under point-source recharge conditions, e. and f. respectively enlargements of $\mathrm{c}$. and $\mathrm{d}$.

Figure 5. Estimated memory effects, corresponding to an autocorrelation coefficient of 0.2 , as a function of the exchange parameter value for the mono- and multi-conduits cases, under diffuse and point-source recharge conditions

Figure 6. Correlation peak as a function of the exchange parameter value for the mono- and multi-conduits cases, under diffuse and point-source recharge conditions

Figure 7. Comparison of the autocorrelation functions calculated for the mono- and multi-conduits cases, under diffuse and point-source recharge conditions with a constant $C_{\mathrm{EX}}=0.75$

\section{Table captions}

Table 1. Modeled domains hydraulic properties 